\title{
Stability Study of Power System
}

\author{
Mohammed Mynuddin ${ }^{1}$, K. M. Roknuzzaman ${ }^{2}$, Prodip Biswas ${ }^{3}$, Mohammad Tanjimuddin ${ }^{4}$ \\ ${ }^{1}$ Dept of EEE,Atish Dipankar University of Science and Technology, Dhaka, Bangladesh \\ ${ }^{2}$ Dept of EEE, Uttara University, Dhaka, Bangladesh \\ ${ }^{3}$ Mobile Lab 2, Samsung R \& D Institute Bangladesh Ltd, Dhaka, Bangladesh \\ ${ }^{4}$ Dept of EEE, Leading University, Sylhet, Bangladesh
}

Email address:

myn101eee@gmail.com (M. Mynuddin),rokon_eee05@yahoo.com (K. M. Roknuzzaman), diip_80@yahoo.com (P. Biswas), tanjim0023@gmail.com (M. Tanjimuddin)

\section{To cite this article:}

Mohammed Mynuddin, K. M. Roknuzzaman, Prodip Biswas, Mohammad Tanjimuddin. Stability Study of Power System. International Journal of Energy and Power Engineering. Vol. 4, No. 2, 2015, pp. 43-50. doi: 10.11648/j.ijepe.20150402.15

\begin{abstract}
The theory of power system stability, necessary of power system stability and different methods for analysis of power system stability has been developed in this paper. The objective of this paper is to investigate and understand the stability of power system, with the main focus on stability theories and power system modeling. The paper first explained the definition of power system stability and the need for power system stability studies. Next the paper examined the concept of system stability and some stability theories. The paper then performed a power system modeling and simulation of a twomachine, three bus power systems. The performance of the power system was simulated. The operating points and system parameters were varied to test the robustness of the power system. From various stability systems, in this paper, only transient analysis is studied. Examples of the parameters that were varied include the fault position $\lambda$, the power angle $\delta$ and the mechanical power input $P_{m}$. A software using MATLAB has been developed for this purpose. Finally we compare various stability responses by varying power angle, fault position and mechanical power.
\end{abstract}

Keywords: Classification of Stability, Control Methods to Prevent Loss of Synchronism, Swinging of Machines, Power System Modeling

\section{Introduction}

An interconnected power system basically consists of several essential components. They are namely the generating units, the transmission lines, the loads, the transformer, static VAR compensators and lastly the HVDC lines. During the operation of the generators, there may be some disturbances such as sustained oscillations in the speed or periodic variations in the torque that is applied to the generator. These disturbances may result in voltage or frequency fluctuation that may affect the other parts of the interconnected power system. External factors, such as lightning, can also cause disturbances to the power system. All these disturbances are termed as faults. When a fault occurs, it causes the motor to lose synchronism if the natural frequency of oscillation coincides with the frequency oscillation of the generators. With these factors in mind, the basic condition for a power system with stability is synchronism. Besides this condition, there are other important conditions such as steady-state stability, transient stability, harmonics and disturbance, collapse of voltage and the loss of reactive power. The stability of an interconnected power system in its ability to return to its normal or stable operation after having been subjected some form of disturbances. The load on the system may change gradually or suddenly. Sudden changes of load may be due to quick switching operation or sudden faults followed by tripping of lines etc. whether or not the system will behave well continue to supply the load and keep the various synchronous machines in step under various conditions is a study by itself and is known as system stability. Stability studies are conducted when new generating and transmitting facilities are planned. The studies are helpful in determining such things as the nature of the relaying system needed, critical clearing time of circuit breakers, voltage level of and transfer capability between systems. The power system industry is a field where there are constant changes. Power industries are restructured to cater to more users at lower prices and better power efficiency. Power systems are becoming more complex as they become inter-connected. Load demand also 
increases linearly with the increase in users. Since stability phenomena limits the transfer capability of the system, there is a need to ensure stability and reliability of the power system due to economic reasons.

The main aim of this paper is to investigate the various power system stability problems, after which one important problem will be singled out for discussion and research. A proposed technique to solve the selected stability problem will also be explained in detail. To maintain synchronism within the distribution system can proved to be difficult as most modern power system are very large. For the purpose of this paper, a simplified two-machine infinite bus power system is studied.

\section{Classification of Stability}

Stability studies are classified into three types depending upon the nature and order of magnitude of the disturbance. These are:

a) Steady state stability

b) Transient stability

c) Dynamic stability

Steady state stability: Steady-state stability is the ability of the power system to regain synchronism after encountering slow and small disturbances. It concerns the stability of the locus of essentially steady state operating points of the system. Example of slow and small disturbances is gradual power changes. Transient stability: It involves major disturbances such as loss of generators, line switching, faults and sudden load changes. The objective of transient stability studies is to determine whether or not the system will remain in synchronism following such disturbances. Dynamic stability: The ability of the power system to regain synchronism after encountering small disturbance within a long time frame is known as dynamic stability. It also concern like steady state stability studies, the stability of the locus of the steady state operating points of the system.

\subsection{Some Control Methods to Prevent Loss of Synchronism}

The performance of a power system is affected when a fault occurs. This will result in insufficient or loss of power. In order to compensate for the fault and resume normal operation, corrective measures must be taken to bring the system back to its stable operating conditions. Controllers are used for this function. Some of the control methods used to prevent loss of synchronism in power systems are [2] [6]:

\subsubsection{Excitation Control}

During a fault the excitation level of the generator drops considerably. The excitation level is increased to counter the fault. An addition of a variable resistor at the terminals of the generator this is to make sure that the power generated is balanced as compared to the power transmitted. An addition of a variable series capacitor to the transmission lines this is to reduce the overall reactance of the line. It will also increase the maximum power transfer capacity of the transmission line.

\subsubsection{Turbine Valve Control}

During a fault the electrical power output $P_{e}$ of the generator decreases considerably. The turbine machine input $P_{m}$ is decreased to counter the decrease of $P_{e}$.

\subsubsection{Improvement of Stability of a System}

Power system stability is defined as that property of the system which enables the synchronous machines of the system to respond to a disturbance from a normal operating condition so as to return to a condition where their operation is again normal. The stability of a power system can be increased as follows by several ways like by designing the governors to follow closely the load on the machines, by designing the excitation systems to give quick adjustment of voltage within limits under transient conditions, by designing the voltage regulators for quick action with a small time constant, by making the exciter relays and regulators fast acting, by making the lines the terminal apparatus stiffer and by including synchronous compensators in the system.

\subsection{Swinging of Machines}

When a major disturbance occurs, an imbalance is created between the generator and the load. The power balance at each generating unit (mechanical input power - electrical input power) differs from generator to generator. As a result, the rotor angles of the machines accelerate or decelerate beyond the synchronous speed of for time greater than zero $(t>0)$. This phenomenon is called the "swinging" of the machines. There are two possible scenarios when the rotor angles are plotted as a function of time: 1. the rotor angle increases together and swings in unison and eventually settles at new angles. As the relative rotor angles do not increases, the system is stable and in synchronism. 2. One or more of the machine angles accelerates faster than the rest of the others. The relative rotor angle diverges as time increase. This condition is considered unstable or losing synchronism. These studies are important in the sense that they are helpful in determining critical information such as critical clearing time of the circuit breakers and the voltage level of the power system.

\section{Equal Area Criterion of Stability}

Equal area criterion of stability is a technique by which the stability of a single machine connected by an infinite bus can be examined under transient condition without solving the swing equation.

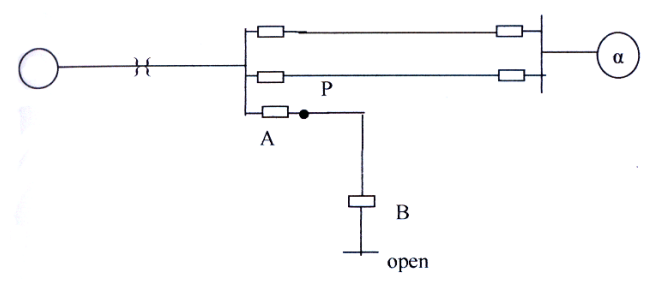

Figure 1. One line diagram of the system 
For determination of stability under transient condition, equal area criterion is applicable only when one machine is swing with respect to an infinite bus. So equal area criterion cannot be used directly in system where three or more machine is represented. For studying the transient system stability of multi-machine, the swing equation for the system should be solved. To do this the following should be done: Reduce the system network (Figure1) to a single equivalent circuit. Determine the transfer-point and driving -point impedance for circuit condition of fault-on, fault-off, etc

Determine initial condition and power flow equation for the various subsequent transient conditions. Determine the acceleration torque constant for each machine group.

\subsection{Transient Stability}

\subsubsection{Mathematical Model}

\section{Swing Equation}

The equation of motion of the rotor of a synchronous machine is

$$
\mathrm{T}_{\mathrm{m}}-\mathrm{T}_{\mathrm{e}}=\mathrm{J} \frac{d \omega}{d t}
$$

Where, $\mathrm{T}_{\mathrm{m}}=$ Shaft torque supplied by the prime mover $(\mathrm{N}$ $\mathrm{m}), \mathrm{T}_{\mathrm{e}}=$ Electric or electromagnetic torque $(\mathrm{N}-\mathrm{m}), \mathrm{J}=$ Moment of inertia $\left(\mathrm{Kg} \mathrm{m}^{2}\right), \frac{d \omega}{d t}=$ angular acceleration, $\theta_{m}=$ Angular displacement of the rotor w.r.to stationary axis on the stator, $\mathrm{T}_{\mathrm{a}}=$ Accelerating torque and $\omega_{s}=$ the synchronous speed of the machine in mechanical radians/sec.

$$
\frac{2 H}{\omega_{s}} \cdot \frac{d^{2} \delta}{d t^{2}}=P_{a}
$$

Equation (2) is called the swing equation.[1]

\subsubsection{Formulation of Power System}

Basic Control Theory

In a control function block, the various parts of the system are broken down into the following function blocks.

(1) The plant, which is the transmission network (2) The fault module (3) The control system, which is the controller

The plant module consists of all the basic function of the transmission system. However it does not include the controller function. Thus the plant module is considered an open loop system as it has no feedback capability. The plant module will also only react to the faults with its own natural dynamics and damping system as it has not have any form of corrective functions. The function of the fault module is to provide the new line impedances and voltages when the fault occurs. The fault module will only generate one value of the line impedance, depending on the location of the fault. The plant module will then receive this value when there is an occurrence of the fault. Otherwise, the plant module will use its original value of line impedance. The controller module provides the feedback to the plant so that adjustment can be made to sustain the fault and regain its synchronism. The block diagrams of a system without controller and a system with control are shown as below.

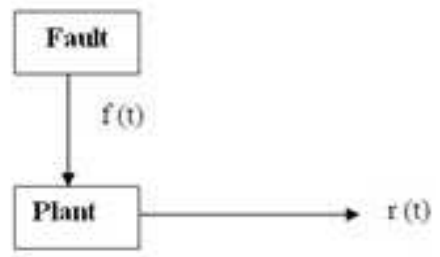

Figure 2. Block diagram of system without control module.

The block diagram in Figure is a simplified closed loop control system. The output of the system $r(t)$ is sent back to the comparator to be compared with the input $\mathrm{u}(\mathrm{t})$. The difference between the feedback and the input e (t) is then fed to the controller. The controller will perform and output the necessary control output y $(\mathrm{t})$ to the plant module. The fault module, which acts as a disturbance, is also fed into the plant module. The cycle is then repeated.

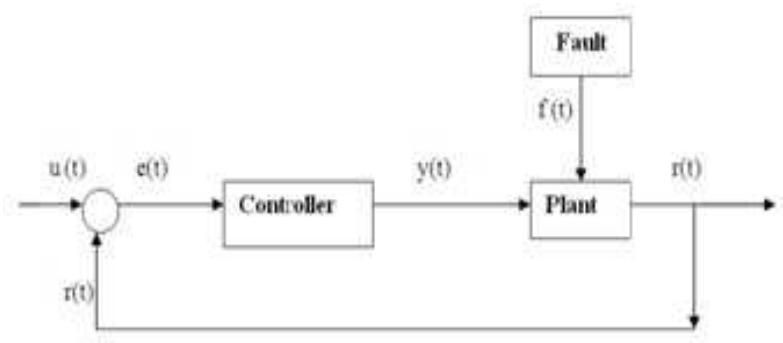

Figure 3. Block diagram of system with controller.

\subsection{Power System Modeling}

The power system modeling is based on a two-machine, three bus power system. The performance of the power system will be simulated with the proposed advanced control technique. The operating points and system parameters will be varied to test the robustness of the power system and the effectiveness of the proposed controller.

The diagram of the model is shown below.

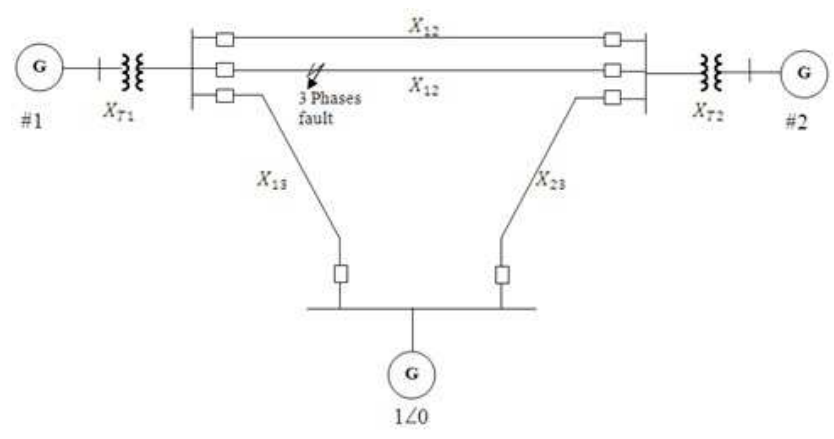

Figure 4. Two-machine infinite bus power system.

\subsection{The Excitation System of an Alternator}

Each and every alternator of a power system is provided with automatic voltage regulator. The primary function of the 
regulator is to supply and automatically adjust the field current of the synchronous machine to maintain the terminal voltage at desired values as the output of the machine varies, while that of a prime mover governing system is to regulate the input power to the turbine of the alternator depending on the change in demand of electrical power. That is why the generator bus bar is treated as voltage controlled (i.e. PV) bus bar.

Excitation control system come in many shapes and varieties. A typical voltage regulator scheme is shown below.

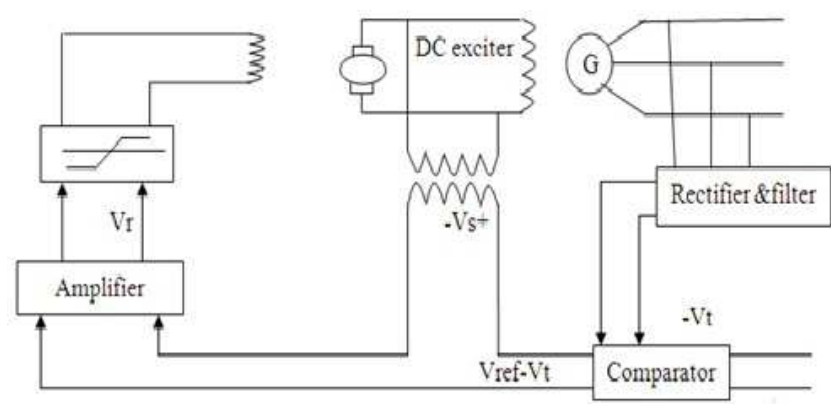

The main alternator is fed through a dc generator which is driven by the same shaft of the alternator itself. The exciter field is controlled via an alternator. The amplifier gets it input from the voltage of an alternator with a reference voltage.

Rectifier is used to convert the ac terminal voltage into dc and the filtered output serves as a signal of the terminal voltage. The block diagram of this system is shown below.

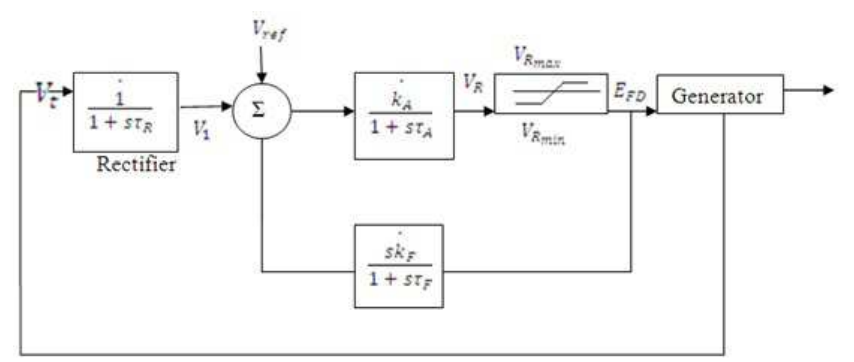

Figure 5. Block diagram of a rectifier.

The filter introduces a time constant $T_{R}$ its value lies in the range of 0.01 to $0.1 \mathrm{sec}$. Amplifier is characterized by a gain factor $K_{A}$ and a time constant $T_{A}$. The transfer function of the amplifier can be obtained from

$$
\begin{gathered}
\mathrm{V}_{R}=\frac{K_{A}}{1+s T_{A}}\left(\mathrm{~V}_{R e f}-\mathrm{V}_{1}-\mathrm{V}_{S}\right) \\
\frac{\mathrm{V}_{R}}{\mathrm{~V}_{R e f}-\mathrm{V}_{1}-\mathrm{V}_{S}}=\frac{K_{A}}{1+s T_{A}}
\end{gathered}
$$

Transfer function $=\frac{\text { output }}{\text { input }}=\frac{\mathrm{V}_{R}}{\mathrm{~V}_{\text {Ref }}-\mathrm{V}_{1}-\mathrm{V}_{S}}=\frac{K_{A}}{1+s T_{A}}$

Usually a high loop gain $K_{A}$ renders the system unstable. Again, with a small amplifier gain, AVR step response is not satisfactory. Thus, in order to improve the relative stability and steady state response, a stabilizing transformer is used. The input is subtracted from the amplifier input. It provides a negative feedback for the stability. The output of the transformer is $\mathrm{V}_{s}$.

$$
\begin{aligned}
& \text { Now, } v_{f}=R_{p} i_{p}+\frac{L_{p} d i_{p}}{\omega \circ d t} \\
& V_{f}=R_{p} I_{p}+\frac{L_{p}}{\omega_{\circ}} S I_{p}[\text { Taking Laplace Transform }] \\
& I_{p}=\frac{V_{f}}{R_{p}+s \frac{L_{p}}{\omega \circ}}
\end{aligned}
$$

And $v_{s}=M \frac{d i_{p}}{d t}$

$$
\begin{gathered}
V_{s}=M s I_{p} \\
\frac{V_{s}}{V_{f}}=\frac{M s}{R_{p}\left(1+\frac{s L_{p}}{\omega \circ R_{p}}\right)} \\
\frac{V_{s}}{V_{f}}=\frac{K_{f} s}{1+s T_{F}}
\end{gathered}
$$

The required equation for the amplifier block are obtained as follows

$$
\frac{d V_{R}}{d t}=-\frac{V_{R}}{T_{A}}+\frac{K_{A}}{T_{A}}\left(\mathrm{~V}_{R e f}-\mathrm{V}_{1}-\mathrm{V}_{S}\right)
$$

Neglecting the rectifier and filter block

$$
\frac{d V_{R}}{d t}=-\frac{V_{R}}{T_{A}}+\frac{K_{A}}{T_{A}}\left(\mathrm{~V}_{R e f}-\mathrm{V}_{1}-\mathrm{V}_{S}\right)
$$

Now, $E_{F D}=V_{R}$ if $V_{R_{\max }}>V_{R}>V_{R_{\max }} \quad, \quad E_{F D}=$ $V_{R_{\max }}$ if $V_{R} \geq V_{R_{\max }}$ and $E_{F D}=V_{R_{\max }}$ if $V_{R} \leq V_{R_{\max }}$

\subsection{Prime Mover Governing System}

When a sudden load comes on the system, the electrical power output of the alternator increases. As a result the shaft speed decreases. The speed governing system senses the change in speed and increases the mechanical power input to the turbine. A typical governor characteristic is shown in the figure:

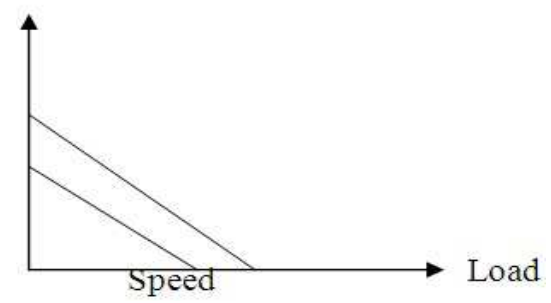

Figure 6. A typical governor characteristic curve

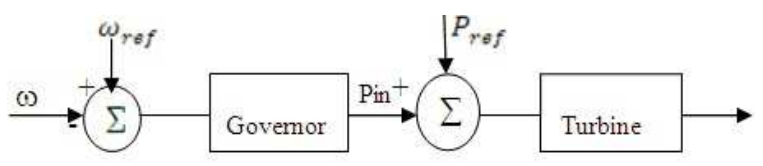

Figure 7. Block diagram of a simple governor-turbine system.

When speed falls i.e. $\omega_{r e f}>\omega, P_{i}$ is + ve. Then $P_{m} \alpha\left(P_{r e f}\right.$ $\left.+P_{i}\right)$ i.e. power output is increased. 
When speed rises i.e. $\omega_{r e f}<\omega, P_{i}$ is - ve. Then $P_{m} \alpha\left(P_{r e f}+\right.$ $\left.\left(-P_{i}\right)\right)$ i.e. power output is decreased.

When speed unchanged i.e. $\omega_{\text {ref }}=\omega, P_{i}=0$. But output power $P_{m} \alpha P_{r e f}$.

\subsection{Governor Model}

When the generator electrical load is suddenly increased, the electrical power exceeds the mechanical power input. The power deficiency is supplied by the K.E. of the rotating system. The reduction in K.E. causes the turbine speed and generator frequency to fall. The change in frequency is sensed by turbine governor acts to adjust the turbine input valve to change the mechanical power output to bring the speed to a new steady state. The most modern governors use electronic means to sense speed changes. A block diagram of modern speed governing system is shown below:

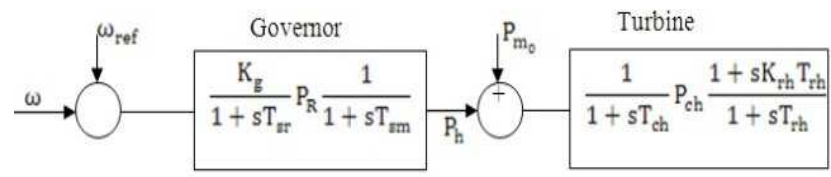

Figure 8. Speed Regulator Speed Mechanism.

The governor consists of two delays. The hydraulic amplifier or speed regulator has the time constant of $T_{s r}=0.1$ $\mathrm{sec}$.The other delay is used for control valve and other speed mechanism where the time constant $T_{s m}=0.2 \mathrm{sec}$. The governor block can be simplified by the gain $K_{g}$ and the time constant $T_{g}=0.2 \mathrm{sec}$.

\subsection{Turbine Model}

The turbine blocks consists of steam chest and reheat turbine sections. After passing through the control valve, the high pressure steam enters the turbine through steam chest. The chest introduces a time delay $T_{c h}$ in the steam flow resulting in transfer function

$$
G_{r}(\mathrm{~s})=\frac{1}{1+s T_{c h}} \text { where, } 0.2<T_{c h}<0.5
$$

Reheat steam turbine type of turbine has several stages between which steam is led via repeaters. The design increases power plant efficiency and is usually accepted in large power plants.

First, it is assumed that two stages are rated gulf total power each. Next, it is assumed that the reheater can be represented by a time constant $T_{r h}$. Then the transfer function becomes

$G_{r h}(\mathrm{~s})=0.5+0.5 * \frac{1}{1+s T_{r h}}=\frac{1+s * 0.5 * T_{r h}}{1+s T_{r h}}\left[0.5=K_{r h}\right]=\frac{1+s * K_{r h} T_{r h}}{1+s T_{r h}}$

State Equation (the 10 differential equation of 10 state variables for transient analysis):

The swing equation can be written as

$$
\dot{\omega}=\frac{1}{M_{g}}\left(P_{m}-D_{g} \omega-P_{e}\right)
$$

The rotor angle equation can be written as

$$
\dot{\delta}=\omega_{0}(\omega-1)
$$

From (figure 5 ) block diagram of rectifier, we have,

$$
\begin{gathered}
V_{R}=\left(V_{\text {ref }}-V_{t}-V_{s}\right) \frac{K_{A}}{1+s T_{A}} \\
\dot{V}_{R}=\frac{1}{T_{A}}\left[-V_{R}+\left(V_{\text {ref }}-V_{t}-V_{S}\right) K_{A}\right]
\end{gathered}
$$

$V_{R}$ is nothing but $E_{F D}, E_{F D}=V_{R \max }$ if $V_{R} \geq$ $V_{R \max }, E_{F D}=V_{R \min }$ if $V_{R} \leq V_{R \min }, E_{F D}=V_{R}$ if $V_{R \min }<V_{R}<V_{R \max }$

$$
E_{F D}^{\cdot}=\frac{1}{T_{A}}\left[-E_{F D}+\left(V_{r e f}-V_{t}-V_{S}\right) K_{A}\right]
$$

Also from figure,

$$
\begin{gathered}
V_{s}=\frac{s K_{F}}{1+s T_{F}} E_{F D} \\
V_{S}=\frac{1}{T_{F}}\left[-V_{S}+\frac{K_{F}}{T_{A}}\left\{-E_{F D}+\left(\left(V_{r e f}-V_{t}-V_{s}\right) K_{A}\right\}\right]\right.
\end{gathered}
$$

Also we have,

$$
\begin{gathered}
E_{d}^{\prime}=\frac{1}{T_{q 0}}\left[-E_{d}^{\prime}-\left(X_{q}-X_{d}^{\prime}\right) I_{q}\right] \\
\dot{E}_{q}^{\prime}=\frac{1}{T_{d 0}^{\prime}}\left[-E_{F D}-E_{q}^{\prime}\left(X_{d}-X_{d}^{\prime}\right) I_{d}\right]
\end{gathered}
$$

From (figure 8), we have,

$$
\begin{gathered}
\left(\omega_{\text {ref }}-\omega\right) \frac{K_{g}}{1+s T_{s r}}=P_{R} \\
\dot{P_{R}}=\frac{1}{T_{s r}}\left[-P_{R}+K_{g}\left(\omega_{\text {ref }}-\omega\right)\right]
\end{gathered}
$$

Again,

$$
\begin{gathered}
P_{h}=\frac{P_{R}}{1+s T_{s m}} \\
\dot{P_{h}}=\frac{1}{T_{s m}}\left[-P_{h}+P_{R}\right]
\end{gathered}
$$

Also, $P_{c h}=\frac{\left(P_{m 0}+P_{h}\right)}{1+s T_{c h}}$

$$
P_{c h}^{\cdot}=\frac{1}{T_{c h}}\left[-P_{c h}+P_{m 0}+P_{h}\right]
$$

Also we have, $P_{m}=\frac{1+s K_{r h} T_{r h}}{1+s T_{r h}} P_{c h}$

$$
\dot{P_{m}}=\frac{1}{T_{r h}}\left[-P_{m}+P_{c h}+\frac{K_{r h} T_{r h}}{T_{c h}}\left(-P_{c h}+P_{m 0}+P_{h}\right)\right]
$$

The parameters that are used in the power system modeling are:

$$
\begin{gathered}
\left.\left.\omega_{0}(\mathrm{rad} / \mathrm{s})=314.159, \mathrm{X}_{12} \text { (p.u. }\right)=0.65, \mathrm{X}_{13} \text { (p.u. }\right)=0.63 \text { and } \\
\left.\mathrm{X}_{23} \text { (p.u. }\right)=0.7
\end{gathered}
$$

For Generator $\# 1$ : $\mathrm{Xd}($ p.u. $)=1.863, \mathrm{X}^{\prime} \mathrm{d}$ (p.u. $)=0.257$, 
$\mathrm{XT}($ p.u. $)=0.129, \mathrm{Xad}($ p.u. $)=1.712, \mathrm{~T}^{\prime} \mathrm{d} 0$ (p.u.) $=6.9, \mathrm{H}(\mathrm{s})=$ 4, $\mathrm{D}$ (p.u.) $=5, \mathrm{~T}_{\mathrm{m}}(\mathrm{s})=0.35, \mathrm{Te}(\mathrm{s})=0.1, \mathrm{R}=0.05, \mathrm{~K}_{\mathrm{m}}=1.0$, $\mathrm{K}_{\mathrm{e}}=1.0$ and $\mathrm{K}_{\mathrm{c}}=1$

For Generator \#2: xd(p.u.) = 2.36, x'd(p.u.) = 0.319, $\mathrm{xT}($ p.u. $)=0.11, \operatorname{xad}($ p.u. $)=1.712, \mathrm{~T}^{\prime} \mathrm{d} 0$ (p.u. $)=7.96, \mathrm{H}(\mathrm{s})=$ 5.1, D(p.u.) $=3, \mathrm{~T}_{\mathrm{m}}(\mathrm{s})=0.35, \mathrm{Te}(\mathrm{s})=0.1, \mathrm{R}=0.05, \mathrm{~K}_{\mathrm{m}}=1.0$, $\mathrm{K}_{\mathrm{e}}=1.0$ and $\mathrm{K}_{\mathrm{c}}=1$

\section{Simulation Results and Discussion}

\subsection{Discussion with Different Cases}

The parameters of the transmission line $V_{t 10}=1.0 \mathrm{p} . \mathrm{u}, V_{t 20}=$ 1.0p.u are used in all cases and others $X_{12}=0.65$ p.u, $X_{13}$ $=0.63 \mathrm{p} . \mathrm{u}, X_{23}=0.7 \mathrm{p}$.u are also used for all cases except case 4(where $X_{12}=0.8$ p.u, $X_{13}=0.8$ p.u, $X_{23}=0.8$ p.u). The others parameters are used for case $1\left(\delta_{10}=0.78, \delta_{20}=0.64, P_{m 10}=\right.$ 0.82p.u, $P_{m 20}=0.9$ p.u, and $\left.\lambda=0.3\right)$, case $2\left(\delta_{10}=28.51, \delta_{20}\right.$ $=33.68, P_{m 10}=0.42 \mathrm{p} . \mathrm{u}, P_{m 20}=0.52 \mathrm{p} . \mathrm{u}$, and $\left.\lambda=0.08\right)$, case $3\left(\delta_{10}=40.5, \delta_{20}=42.5, P_{m 10}=0.67\right.$ p.u, $P_{m 20}=0.66$ p.u, and $\lambda$ $=0.08)$ and $\delta_{10}=74.08, \delta_{20}=75.33, P_{m 10}=0.85$ p.u, $P_{m 20}=$ 0.85 p.u, and $\lambda=0.8$ are the same for case $4 \& 5$.
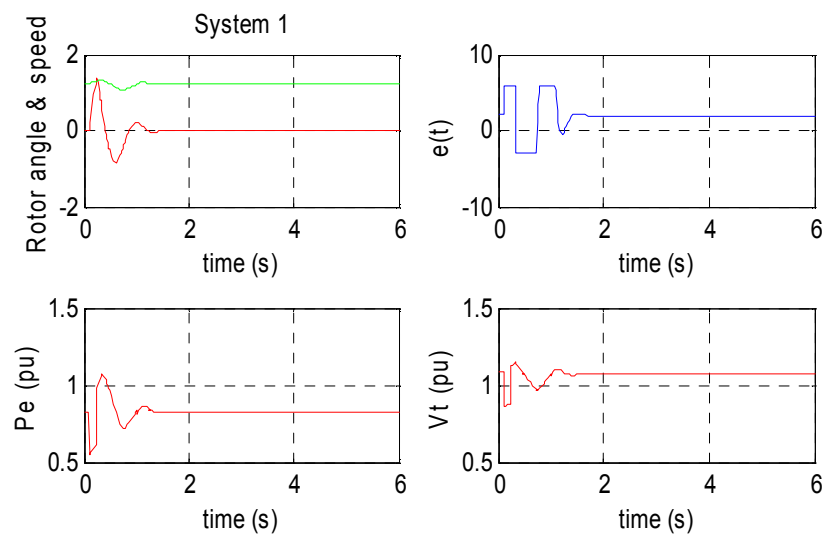

Figure 9a. Results of System 1(Case 1)
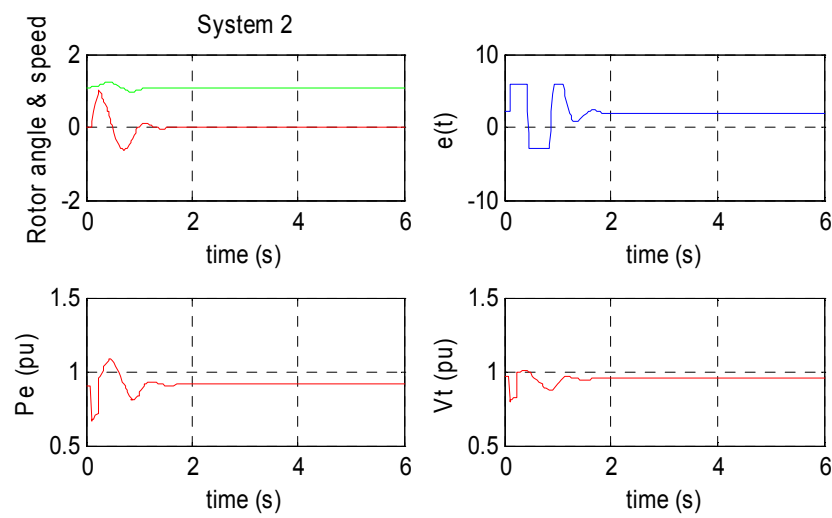

Figure 9b. Results of System 2(Case 1)
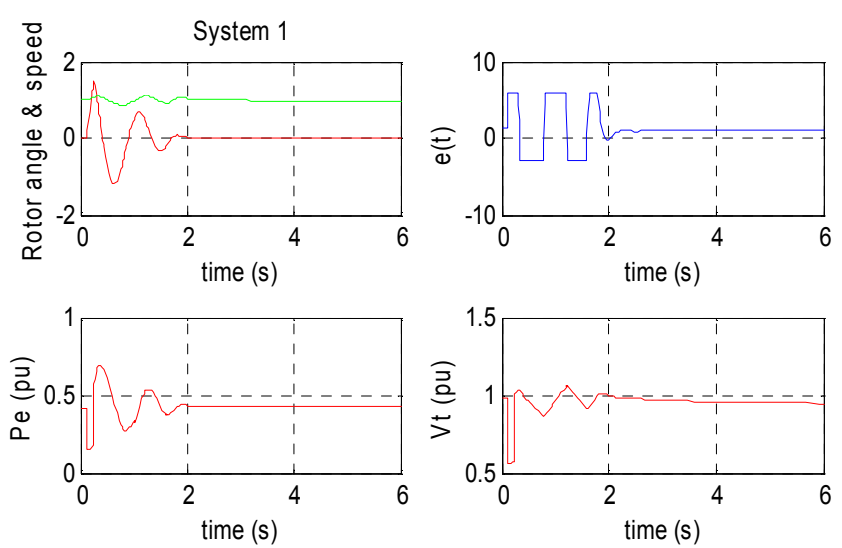

Figure 10a. Results of System 1. (Case 2)
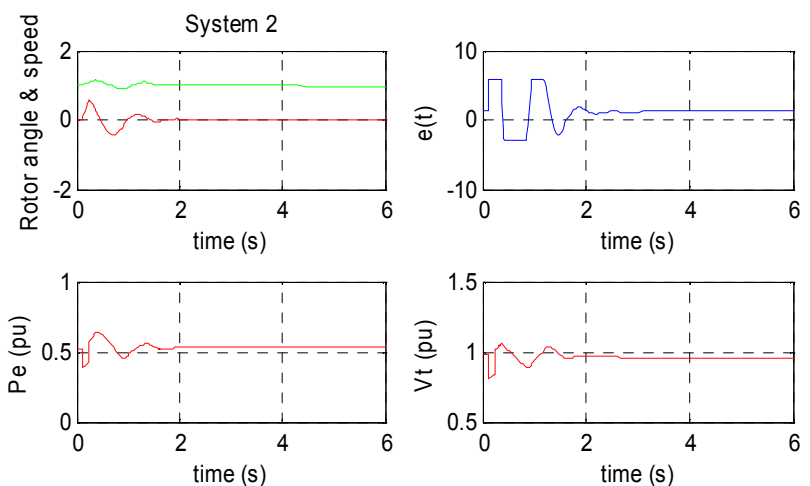

Figure 10b. Results of System 2(Case 2)
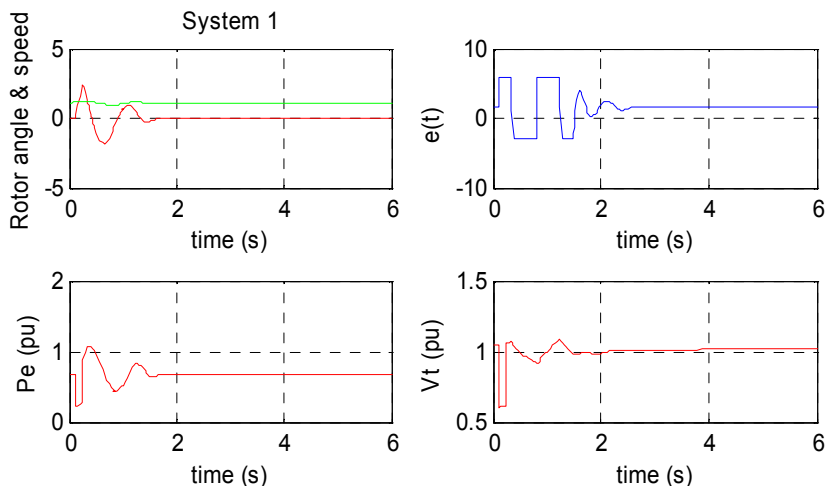

Figure 11a. Results of System 1 (Case 3)
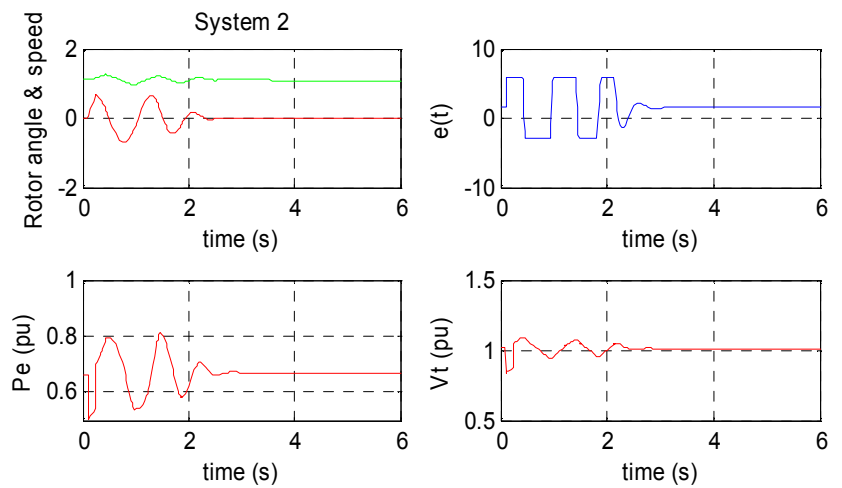

Figure 11b. Results of System 2 (Case 3) 

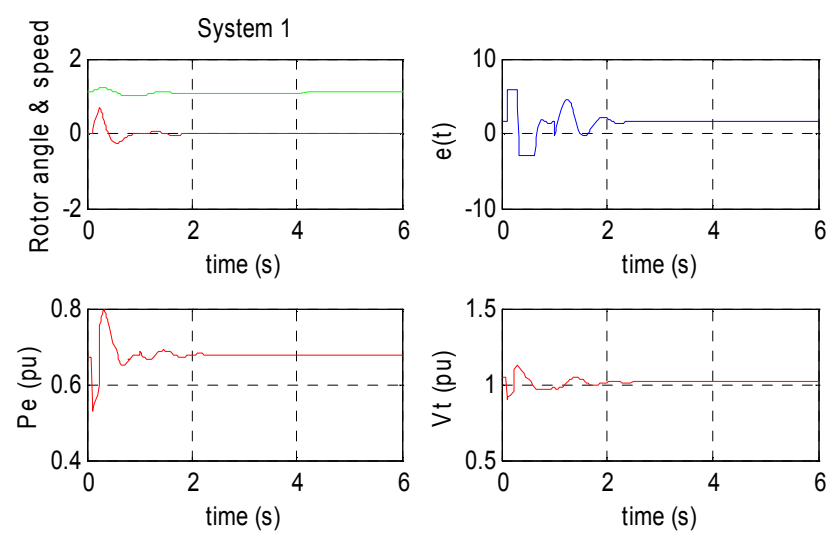

Figure 12a. Results of System 1 (Case 4)
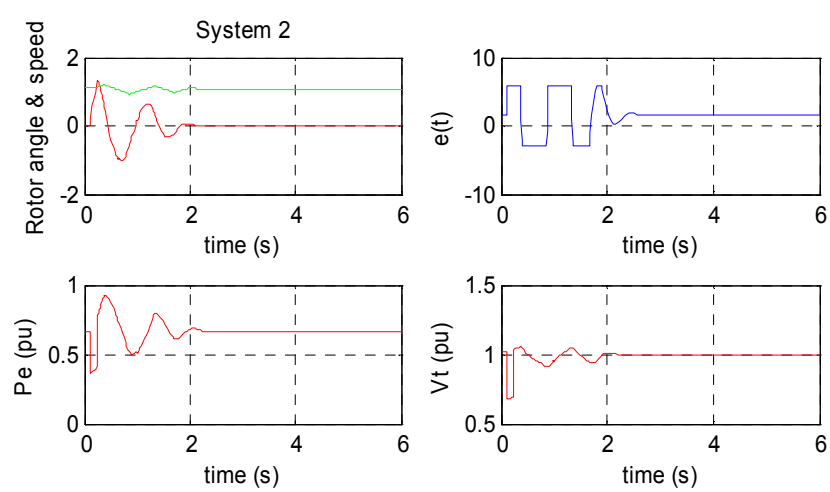

Figure 12b. Results of System 2 (Case 4)
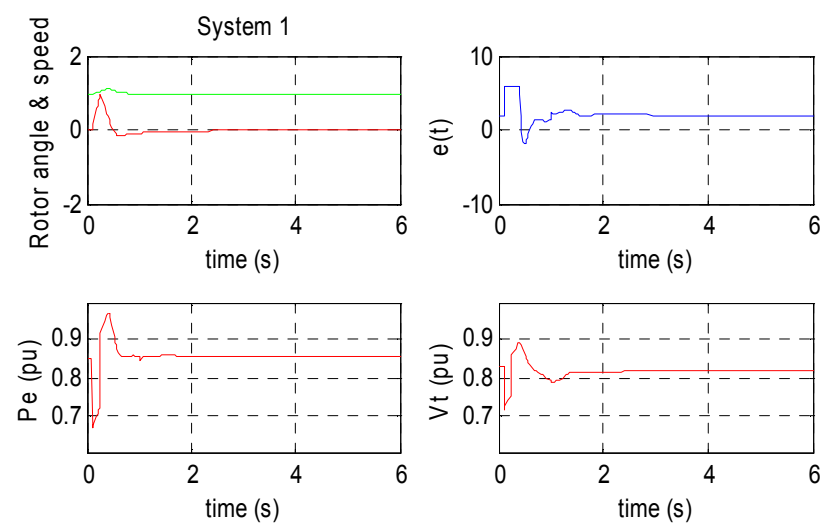

Figure 13a. Results of System 1. (Case 5)
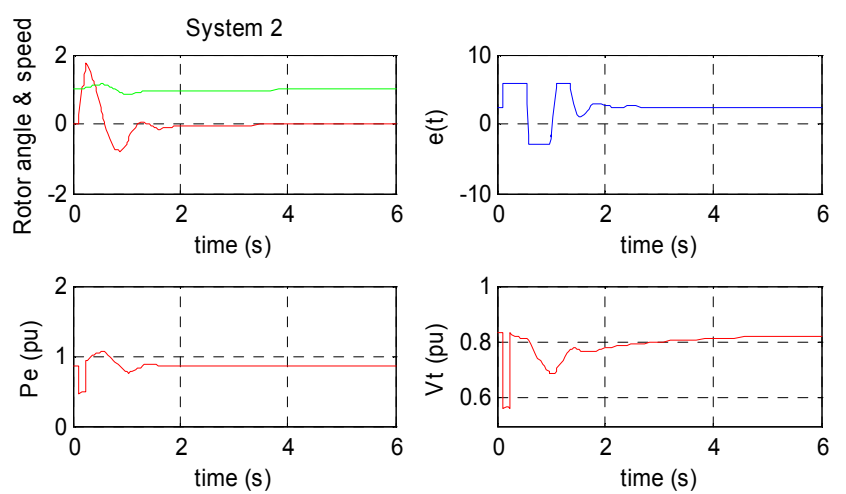

\subsection{Case}

From the various simulation results, it can be seen that when the symmetrical three-phase short circuit fault occurs at the transmission line between Generator 1 and Generator 2 at $\lambda=0.3$, the condition of the system is very unstable(figure.4). There is an effect on the EMF in the quadrature axis Eq. This will in turn affect the value of the electrical power $P_{e}$. With the change in $P_{e}$, the swing equation will change accordingly and the acceleration of the system will be affected. Likewise, both the power angle $\delta$ and relative speed $\omega$ will be affected. When the three phase symmetrical fault occurs at $\mathrm{t}=0.1 \mathrm{sec}$, we can see a sudden drop in $P_{e}$ due to the reduction in line impedances. Also, as the current at the line where the fault occur is able to find another route with relatively less impedance to flow, it results in the fluctuation in $V_{t}$. The oscillation shown in the relative speed and the power angle is the result of the natural damping of the system. The system tries to regain synchronism after encountering the fault. The system model is again unable to regain its synchronism upon encountering the fault. The condition of the system is unstable. The results yield from Case 3 is similar to the results from Case 1 and 2. The system model is unable to regain its synchronism upon the occurrence of a fault. However comparing the above results with the results from Case 2, it can assume that the level of disturbance in Case 3 is higher. The results shown above are again similar to the previous cases that were discussed earlier. The system model is unable to sustain the fault and loses its synchronism. Here the condition of the system model is unstable. The system is unable to sustain its equilibrium after the occurrence of the fault.

\subsection{Discussion}

This thesis attempted to provide an insight into the various power system stability issues. In the first part of the thesis, the definition of power system stability was discussed. Several reasons were also provided to justify the need to study the area power system stability. It has been stated earlier that the objective of this thesis is to develop a computer program by MATLAB that can simulate the response of the power system considering the variation of parameters during three phase symmetrical fault.

\section{Glossary of Principal Symbols}

$X_{12}, X_{13}, X_{23}=$ Reactance of transmission line

$\delta_{10}, \delta_{20}=$ Power angle

$P_{m 10}, P_{m 20}=$ Mechanical power

$V_{t 10}, V_{t 20}=$ Terminal voltage of generator

$\lambda=$ Fault position

$P_{e}=$ electrical power

$V_{t}=$ terminal voltage

Figure 13b. Results of System 2 (Case 5) 


\section{References}

[1] "Elements of power system analysis", Stevenson W.D.Jr, $\left(4^{\text {th }}\right.$ Edition).

[2] "Power System Analysis", H. Saadat.

[3] "Electric energy systems theory", Elgerd, O.I, ( $2^{\text {nd }}$ Edition).

[4] "Electrical of power system design". Despande, M.V, ( $1^{\text {st }}$ Edition)

[5] "Computer methods in power system analysis", Stagg, G.W., El-Abiad, A.H,

[6] "Power System Stability Enhancement by Variable Series Compensation", S S Choi, G Shrestha and F Jiang.
[7] "Power System Stability", M .A Pai.

[8] “Power System Stability”,L. Z. Racz and B. Bokay.

[9] "Energy Functions, Transient Stability and Voltage Behaviour in Power System with Non-Linear Loads", I. A. Hiskens and D. J. Hills.

[10] "Voltage Stability Indices for Stressed Power System", P. A Lof and G. Andersson.

[11] "Transient Stability Enhancement and Voltage Regulation of Power System", Y. Y. Wang, L. Gao, D. J. Hills and R. H. Middleton.

[12] "Stability Theory for Differential/ Algebraic Systems with Application to Power System", D. J. Hill and I. M. Y. Mareels.

[13] "Dynamic Analysis of Voltage Collapse in Power Systems", D. J. Hills and I. A. Hiskens. 